\title{
LA IMPUGNACION DE LOS ACTOS DE LA ADMINISTRACION POR JUBILACION ANTICIPADA DE LOS FUNCIONARIOS PUBLICOS
}

\author{
POR \\ ERNESTO GARcia ARILLA \\ Doctor en Derecho
}

SUMARIO: I. Planteamiento. II. Consideraciones. III. Varios criterios doctrinales. IV. Aspectos legales. V. Sugerencias sobre otras vías de impugnación. VI. Motivaciones jurídicas y procesales. VII. Conclusion.

El estudio de este tema por su actualidad y afectación a tantos funcionarios da la impresión de que sobre el mismo queda poco por decir, de estar legal y jurídicamente agotado, sancionado, sin que al parecer merezca la pena reconsiderarlo.

Somos conscientes de que las dudas que vertemos en este trabajo habrán sido ya, o serán en breve, superadas y aclaradas por ilustres compañeros de mejor pluma, por lo que agradecemos afectuosamente a la Junta Colegial y a los responsables de esta Revista la deferencia que con su publicación han dispensado a estas cuartillas.

El precedente y las directrices enmarcadas en las recientes sentencias del Tribunal Constitucional y del Tribunal Supremo sobre anticipación de la edad de jubilación de los funcionarios públicos, así como el efecto de "santidad» juzgada que estos fallos judiciales proclaman han mermado, sin duda, el ánimo de esos jubilados y posiblemente reducido el interés por su estudio de juristas y tratadistas pues, no en vano, tales pronunciamientos dimanan de las dos más altas instancias del Poder Judicial. $Y$ esto supone un signo negativo por cuanto la problemática que esas cuestiones plantean suele tener una muy acusada proyección social, legal y hasta política.

\section{I.. PLANTEAMIENTO}

Un funcionario ingresa en la Administración pública por oposición directa a tenor de las bases aprobadas por el Ministerio equis, publicadas en el «Boletín Oficial del Estado» equis, tomando posesión de la plaza en propiedad de su primer destino, y quedando integrado en el escalafón.

Desde su incorporación desempeña el cargo ininterrumpidamente hasta la jubilación forzosa por edad, por acuerdo en la Administración a quien sirve, fijándole una pensión con arreglo a la Ley de Medidas Urgentes de Reforma de la Función Pública de 1984. 
El ordenamiento legal vigente regulador de la materia bđjo el cual se produce el ingreso del funcionario era anterior a la entrada en vigor de la susodicha Ley.

Esas disposiciones recogían entre otros inherentes a la plaza de nuevo ingreso en el momento de su incorporación e investidura los siguientes derechos:

- Derecho al cargo y permanencia en él durante y hasta que se cumplieran los setenta años de edad.

- Inamovilidad hasta la jubilación forzosa a la edad de setenta años.

- Devengo de haberes activos y pasivos hasta los setenta años de edad y los últimos hasta el fallecimiento.

La repetida Ley Sobre Medidas Urgentes de la Función Pública de 1984 establece imperativamente para esos funcionarios el tope máximo de jubilación a los sesenta y cinco años.

\section{CONSIDERACIONES}

Esa relación funcionarial estatutaria y, en cualquier caso, bilateral de compromiso mutuo, entre la Administración y el funcionario, es alterada unilateralmente por el Estado o por subrogación o delegación por las entidades públicas que dictan y ejecutan el acto declaratorio de jubilación; acto que como veremos adolece de vicio de legalidad en razón a que la Administración, sin causa o interés público que lo motive, anticipa en cinco años el tiempo de permanencia en el cargo estableciendo a motu propio la edad de jubilación forzosa en sesenta y cinco años en lugar de los setenta, modifica de oficio las condiciones preestablecidas e infringe el ordenamiento legal $y$ jurídico aplicable en pugna con las propias bases de la oposición e incurre en flagrante desvío de poder, al no respetar los derechos del funcionario subsistentes a su ingreso.

Esas resoluciones quiebran los principios de igualdad y equilibrio estatutario en la relación de servicio entre Administración y funcionario y consuman un perjuicio o minoración de sus haberes por lucro o beneficio cesante; no se adecúan como veremos a las facultades y potestades de la Administración ni garantizan ni respetan como procedía las condiciones del tácito pacto legal o compromiso de origen del que germinaron prestaciones recíprocas dimanantes de la vinculación al servicio de la Función pública.

El quantum económico de esa minoración de ingresos, como igualmente razonaremos, es susceptible de cifrar por medio de una operación aritmética, restando el importe total de la pensión de jubilación que se le fija globalmente al funcionario calculada por el 
tiempo de los cinco años suprimidos - sustraendo-, de la que hubiera percibido durante ese quinquenio, de no haberse producido la anticipación de la jubilación forzosa a los setenta años - minuendo.

El hecho implica, pues, una expropiación ilegal sin indemnización o acto confiscatorio que empobrece el patrimonio del recurrente $y$ conlleva a un anormal e ilegal beneficio o enriquecimiento injusto para la Administración que se ve lucrada con unos ingresos hurtados de los beneficios que por ley correspondian al funcionario.

Estos actos objetivamente no merecen otra calificación que la de ilegales, antijurídicos y arbitrarios.

Obviamente que partimos de la presunción de que el funcionario no ha sido sometido en el ejercicio de sus funciones a ningún expediente disciplinario ni se produjo, ni por ese motivo ni por otras causas, interrupción alguna en el transcurso de su vida activa profesional, habiendo rendido puntualmente impuestos, cuotas mutuales y demás gabelas propias de su condición durante este período.

También ha de presumirse - de hecho en la casi totalidad de los casos así es - que esa aportación tributaria se calcula en función al tiempo de permanencia por el límite máximo de edad de jubilación forzosa a los setenta años, es decir, como se ha indicado cinco años más de los que la Administración le ha privado al imponer el tope máximo de los sesenta y cinco.

\section{VARIOS CRITERIOS DOCTRINALES}

Garcia TreVijano en su obra Tratado de Derecho Administrativo acopia sintetizados los criterios de algunos tratadistas sobre la relación Administración-funcionario y entre ellos cita a JELINEK, ROYO Villanova, fernandez Velasco, Garcia OViedo, Gascón y Marin, JoRdANA DE POZAS, SERRANO GUIRADO, significando la evolución histórica legal y destacando la dispar corriente de las distintas directrices sustentadas por esos autores respecto de la naturaleza jurídica de la susodicha relación sobre las prestaciones recíprocas que de la misma surgen.

Estos criterios los resumimos asi: predominio de la prerrogativa de la Administración de matiz absolutista en la Edad Media hasta el siglo XVIII en la que no existe base contractual ni plano de igualdad; se trata de una relación «política» unilateral y excluyente a favor de la Administración que considera al funcionario-prestatario como un sometido servidor; esta corriente discurre al socaire de los diversos procesos políticos del Estado, y determina lo que la doctrina califica de relación estatutaria, esencialmente consolidada más tarde en el régimen legal francés; en ella se elude el concepto del derecho 
«adquirido» y apenas se aceptan unas expectativas económicas de futuro que son susceptibles de alterear por la omnímoda voluntad de la Administración o del poder legislativo - Ius-Variandi.

Paralela y alternativamente florecía otra corriente doctrinal que atribuye a la relación Administración-funcionario el carácter de trabajo especial de servicio - in tuite personae-, bilateral, de la que se desprenden prerrogativas para el Estado y derechos del funcionario a costa del primero; ya entre esos derechos se atisba los de fijeza e inamovilidad, la permanencia en el cargo con un límite máximo de retiro forzoso por edad, normado, de aplicación objetiva y de efectos subjetivos en las retribuciones del empleado; se le aseguran unos haberes pasivos que una vez consolidados con el tiempo escapan del libre albedrío y potestad de la Administración. Se tipifica así una relación entre dos - cuasi contractual--, equiparable o asimilable a la reciprocidad de derechos y prestaciones de la concesión pública en la que el concesionario subrogado en algunas potestades públicas se obliga a prestar a plazo cierto un servicio público en sustitución o subrogando al Estado; viene a configurarse como la de un gestor de servicio público sujeto a un término predeterminado - concertadode cuya relación emanan igualmente derechos y deberes.

A idéntica similitud responde la modalidad contractual del mandato para ejercer funciones públicas o a otras figuras de naturaleza jurídica parecida que se dan en la prestación de servicios a la Administración.

GARCíA TREVIJANO cita algunas resoluciones del Alto Tribunal español, como las sentencias de 23 de marzo de 1934, 3 de abril de 1936, 21 de mayo y 3 de noviembre de 1952, Sala Quinta, en las que se advierte la consagración en nuestro Derecho de la relación unilateral, pero sin excluir del todo las expectativas de aquellos derechos como el de permanencia, inamovilidad $y$ tope máximo $y$ mínimo para consolidar haberes.

Es evidente que el funcionario no puede, a su capricho, dilatar su vida profesional más allá de los términos que la ley le fijó y que aceptó al adherirse al compromiso prerreglado que la Administración le ofrece en la convocatoria de ingreso, y obviamente la Administración tampoco está legitimada per se para disponer a su voluntad del futuro profesional del funcionario sin incurrir en desviación de su potestad y del fin público que patrocina consistente en la selección de un funcionario cualificado, capacitado, que sometido a pruebas de aptitud, esfuerzo físico o intelectual debe ser protegido con las garantías mínimas del régimen legal de todo Estado social, democrático y constitucional.

Si así no se entendiera se daría la aberración de que el Poder público podría destituir o cesar discrecionalmente al funcionario un 
instante después de su toma de posesión, y sea cual fuere el tiempo transcurrido desde su incorporación y sin compensación alguna.

\section{ASPECTOS LEGALES}

La innovación que ha supuesto la Ley de Funcionarios Públicos de 1964 y la novísima no menos discutida y conflictiva de las Medidas Urgentes de la Función Pública de 1984 han trastocado peligrosa y perjudicialmente para los funcionarios públicos ingresados en la Administración con anterioridad a la promulgación de esta última su estabilidad jurídica de origen; y no porque esta Ley sea pródiga en claridad y equidad y constituya un dechado de respeto para los "derechos adquiridos» del funcionario, que no lo es, sino porque a la vez adolece de inexplicables vicios en su elaboración y del grave y esencial defecto de no contemplar o dedicar como era preceptivo una específica Normativa Transitoria reguladora de las situaciones de hecho y de derecho consumadas de todo el personal activo subsistente de la Función pública y afectándoles y perjudicándoles retroactivamente.

De ahí las discutibles sentencias a que nos hemos referido del Tribunal Constitucional y del Supremo vacilantes y dando pie a disparidad de criterios; unos propendiendo a favor de directrices progresistas yugulando el denominado «derecho adquirido" cuyo mayor "pecado» puede estar, como se indica, en retrotraer su vigencia y efectos a esas situaciones anteriores a la promulgación de la ley; otros, abogando por el tradicional precedente jurídico de irretroactividad en lo que no suponga ventaja o beneficio - creemos que los más-. negando vigencia a dicha Ley y desvirtuándola, confiriéndole únicamente eficacia ex tunc, es decir, a partir de su entrada en vigor para situaciones de futuro, y excluyendo a los funcionarios ingresados con anterioridad.

Sería negar la evidencia de que ese funcionariado adquirió tal condición de funcionario al amparo de unos principios de Derecho inmutables, consagrados por el existente y vigente ordenamiento legal y político con la esperanza de su permanencia y seguridad jurídica ante y frente a la Administración que los nombró y a la que subsistiera posteriormente sea cual fuere el régimen político imperante.

El propio GARCIA TREVIJANO recopila también algunas disposiciones y sentencias como la de 2 de marzo y 13 de octubre de 1959; 5 de abril de 1962; 4 de marzo de 1965; 7 de enero de 1960; 1 de agosto de 1960; 26 de junio de 1963; 26 de febrero de 1968 -sobre «trienios»- y de 15 de marzo y 9 de febrero de 1946 que con la de 21 de marzo de 1959 confirman aquella oscilación. 
Los dictámenes del Consejo de Estado de 9 de febrero y noviembre de 1946 y el de 21 de marzo de 1959 que cita inclinan a favor de la Administración la potestas variandi prueba de la evolución y reconversión de esa corriente que pone de manifiesto la confusión y la carencia de un estatuto legal estable, equitativo y justo para los funcionarios de procedencia anterior.

Así, pues, el funcionario no detrae su derecho sólo de la normativa. vigente en el momento de su nombramiento sino también por un compromiso de adhesión hacia la Administración de cuya conjunción de actos libres dimanan derechos, deberes y obligaciones recíprocas; la primera al reglamentar el proceso de selección exigiendo a los aspirantes -opositores o concursantes - la práctica de pruebas o ejercicios que tras su evaluación resuelve optar por el de superior. puntuación - teórica y legalmente el mejor-y el opositor-aspirante, por su decisión espontánea de sumisión a esas reglas mediante un acto voluntario que elige y decide de ser funcionario tras su nombramiento y toma de posesión. Surge, pues, una relación y vinculación mutua de prestaciones que está previsto perdure por el período que el ordenamiento legal aplicable tenía establecido; es por ello -insistimos - el que ese nexo obligacional debe ser mantenido $y$ «conservado", por el tiempo mínimo prevenido hasta que el natural y automático transcurso del tiempo el funcionario cumpla la edad de setenta años. De no aceptarse asi contra todo principio de derecho ese funcionario quedaría a merced de la Administración.

Es indudable que ese tope final puede verse alterado de surgir circunstancias eventuales, especiales $u$ optativas de interés público para la Administración o para el funcionario como pudieran ser la jubilación voluntaria a su instancia; por cese en caso de expediente disciplinario y sanción de destitución; fallecimiento anticipado u otra causa impuesta legalmente o acaecida súbitamente ajena a la libre voluntad de las partes y siempre, si se aduce por la Administración, por motivos de interés general público y acatando su propia reglamentación.

Si ello no ocurre y es la Administración quien provoca unilateralmente el cese anticipado debe quedar obligada a probar la concurrencia de una causa justa y a respetar y reconocer el compromiso adquirido; compromiso como se ha dicho del que devienen para el funcionario el derecho al cargo, la permanencia en la función, la seguridad jurídica retributiva en el ámbito de los haberes activos y pasivos y esencialmente la no pérdida de unos legítimos beneficios económicos como efecto final.

Y esto es así porque de invocarse un interés público o general como sucede con la supresión o reducción de plantillas, extinción de puestos de trabajo, etc., imperativamente la propia Ley obliga a la 
Administración a declarar de oficio la «expropiación» de esos derechos y consecuentemente:

A la compensación o indemnización al funcionario excedente o "expropiado" y cesado fijada con equidad y precio justo.

A determinar la situación administrativa de expectativa de un nuevo destino con percepción ininterrumpida de devengos, retribuciones $u$ otros emolumentos que la propia Ley estipula durante el término o plazo no inferior al fijado y previsto legalmente en la fecha de la asunción del cargo por el funcionario.

A reservar el derecho de prioridad o preferencia sobre otros aspirantes de menor antigüedad en caso de reingreso por posterior convocatoria o en concurso de traslado.

Ignoramos, pues, o discrepamos de quien opine lo contrario acerca de que ese ordenamiento anterior haya sido derogado expresa y específicamente; ni por la Ley de la Función Pública, ni por otras especiales, como sería lo preceptivo - la derogación de la ley especial requiere otra de igual rango y carácter sin que sea factible hacerlo por una ley ordinaria-, para prescindir o dejar sin efecto toda la normativa concreta que integra la gama de funcionarios a que nos estamos refiriendo.

Precedentes equiparables son los acaecidos a la extinción o cesación del funcionariado sindical del régimen anterior; los que estatuye la propia Ley de la Función Pública recogiendo en sus normas transitorias fórmulas transaccionales $u$ opcionales como la indemnización global por una vez; la de continuar con retribución congelada o la excedencia forzosa, por extinción o integración de Cuerpos, con los devengos que la misma ley según la condición de los funcionarios se encarga de regular.

Los funcionarios del suprimido Servicio de Inspección y Asesoramiento de las Corporaciones locales fueron compensados económicamente por decisión del Tribunal Supremo, con indemnizaciones logradas por vía judicial proporcionales a los beneficios retributivos que tras su cese esos funcionarios demostraron dejaron de percibir a causa de la extinción por la Administración de aquel servicio.

Constituye precedente también las indemnizaciones otorgadas por sentencia judicial a funcionarios a quienes la aplicación de la Ley de la Función Pública les sorprendió en una determinada edad, consistente en varias mensualidades, y que no cabe entender se trate de "Subvenciones» o "donativos" sino consecuencia de una medida excepcional de la Administración que vino a extorsionar a trueque de un posible interés público las expectativas de la relación de prestaciones con esos funcionarios. 


\section{SUGERENCIAS SOBRE OTRAS VIAS DE IMPUGNACION}

El precedente de los pronunciamientos desestimatorios del Tribunal Constitucional y del Tribunal Supremo posteriores a la Ley de la Función Pública en materia de jubilación por edad anticipada a los sesenta y cinco años, obliga a condicionar el seguimiento procesal y competencial de nuevas impugnaciones, arbitrando otras vías de recurso que las utilizadas en esos procesos a fin de eludir y no incurrir en los mismos argumentos $y$, por lo tanto, en iguales fallos negativos. De ahí que nos atrevamos hipotéticamente a sugerir la posibilidad de apelar al procedimiento ordinario contenciosoadministrativo pero con pedimentos distintos al de «inconstitucionalidad» de la Ley de la Función Pública o del "Derecho Adquirido" y también por exclusión desechemos el trámite de la Ley Especial Procesal 62/1978 por la eventualidad de declararse la inadmisibilidad del recurso al considerar el Tribunal que la pretensión no ampara un derecho fundamental, como ya se ha sancionado.

Habrá que huir igualmente del procedimiento para la reclamación de daños y perjuicios previo al ejercicio de la acción declarativa ante la jurisdicción ordinaria civil por la posibilidad cautelar de ser excepcionados de incompetencia, al estar asimismo sentenciada la procedencia de esta jurisdicción contencioso-administrativa para lograr esa pretensión.

Lo anterior no descarta la previsión de utilizar en su caso el recurso subjetivo de amparo constitucional o los extraordinarios ante los Tribunales Internacionales de Derechos Humanos, Defensor del Pueblo o de Justicia en cada Comunidad Autónoma, que no excluyan tales vías por haber ejercitado el recurso ordinario contenciosoadministrativo.

Si tras esos procesos no se consigue nada, salvando los errores en los que posiblemente en este trabajo estamos incurriendo, no tendriamos más salida ni otro consuelo que aferrarnos al aforismo: Lex injusta non est Lex.

\section{MOTIVACIONES JURIDICAS Y PROCESALES}

Los fundamentos legales a esgrimir como soporte jurídico de la impugnación serían:

La Jurisdicción y competencia vendrán atribuidas a la jurisdicción contencioso-administrativa, Sala correspondiente de la Audiencia Territorial (arts. 1, 10 y 11 de la Ley Jurisdiccional).

Teóricamente no existe posibilidad legal de oponer la Administración en el proceso las excepciones de los artículos 2.9 y 40 de dicha 
Ley obstaculizando para la admisión, conocimiento y resolución del recurso porque como se han expresado las vías procesales son otras de las seguidas en los pleitos cuyas pretensiones formal o sustancialmente fueron rechazadas.

La personalidad y legitimación del reclamante se acreditará con los documentos susceptibles de aportar al promoverse la reclamación formulando la manifestación de remisión al expediente profesional del recurrente al no obrar esa prueba en poder del interesado.

El motivo principal descansará en solicitar de la Administración declaración sobre la situación y relación fáctica y jurídica entre la Administración y el funcionario, y denunciar la vulneración de disposiciones legales, bien por dejarlas de aplicar, bien por dictar la Administración actos o resoluciones al amparo de normas improcedentes. La Ley de la Función Pública no tiene por qué afectar o esgrimirse en la pugna derivada de las relaciones de la Administración con el funcionario puesto que la actuación de la primera no se ajusta a derecho ni se atiene al ordenamiento jurídico y legal aplicable (arts. 28, 32, 39 y art. 47 de la Ley de Procedimiento Administrativo).

Para que procesalmente el recurso quede expedito se acreditará documentalmente que ha sido apurada la vía gubernativa ante la Administración sin que quepa ulterior recurso a superiores instancias (art. 40 de la Ley Jurisdiccional).

En el caso de que la Administración no se haya pronunciado aún en esa vía, quedará abierto el cauce procesal del recurso interponiéndolo dentro de los términos requeridos por los artículos 38, 52 o 53 aplicables en el supuesto de silencio o acto tácito denegatorio.

La cuantía del pleito se tendrá como indeterminada a efectos procesales y fiscales, ya que el importe líquido de esa cantidad habrá de fijarse según las bases reflejadas en el cuerpo del recurso y en el incidente de ejecución de sentencia (art. 49 de la susodicha Ley).

Este punto constituye a nuestro juicio otra cuestión importante para la viabilidad de la reclamación, y por ello reiteramos, que el quantum líquido y concreto de la minoración de beneficios se determinará deduciendo la diferencia entre el total íntegro o suma de los emolumentos básicos complementos e incentivos reglamentarios fijos y periódicos - no personales - asignados a la plaza en presupuesto en la fecha en que el recurrente cumplía los sesenta y cinco años y que hubiera como mínimo devengado durante el período de los cinco años hasta los setenta y la cantidad que por ese mismo período habría de percibir, calculada en razón a la cuantía de la pensión que le ha sido fijada por las resoluciones ya impugnadas.

El montante de esa diferencia constituirá el total importe evaluado económicamente de lo que al recurrente le corresponderá en justicia percibir en conceptos de pago o indemnización compensatoria por los 
beneficios que le han sido minorados a causa de su jubilación anticipada.

En esa operación convendrá prever los incrementos legales autorizados con carácter general en los presupuestos del Estado para todos los funcionarios públicos en cada ejercicio como adecuación al coste normal de vida, precios de consumo u otros que taxativamente se fijan por ley.

El pago de la cantidad que se logre en la sentencia se hará efectiva bien prorrateada por períodos mensuales coincidentes con el cobro del haber pasivo del funcionario durante el tiempo de los cinco años que le resten hasta el cumplimiento de los setenta o bien de una vez en la forma que reglamentariamente tiene establecida la Administración pública para esa clase de pagos.

Una cuestión relevante que podría excepcionar la Administración sobre la legitimidad del recurso es el impedimento excepcional de los artículos 5. y 6. de la Ley Orgánica del Poder Judicial 6/1985, de 1 de julio, que priva a jueces y tribunales de aplicar la. ley o cualquier otra disposición contraria a la Constitución o en pugna con el principio de jerarquía normativa.

Mas ese riesgo creemos se soslaya porque, como se ha apuntado, la pretensión del recurso no se ampara en la inconstitucionalidad de la ley, concretamente la de Medidas Urgentes de la Reforma de la Función Pública de 1984, sobre jubilación anticipada por edad, ni en otra disposición de igual o semejante rango que impida al Tribunal entrar a considerar y fallar las cuestiones planteadas; ni tampoco se propugna dilucidar sobre la existencia de supuestos «derechos adquiridos" en base a una determinada Ley; ni siquiera la de tratar de esclarecer si lo que se pida en el suplico proviene esencial y directamente de una norma o de un contrato.

Como se ha reiterado to que se solicita fluye del ordenamiento legal y jurídico, y de la relación que el propio poder legislativo sancionó y no derogó expresamente.

Derogare legi est cum detrahitur pars; Abrogatur cum legis tollitur prorsus.

Specialia generalibus derogant; pero no a la inversa.

De neta y vieja tradición jurídica es el aforismo «la esperanza es un derecho".

In estipulationibus id tempus spectatur quo coitrahimos. (Digesto libro L. Título XVII ley 144, pág. 144, párrafo 1.ำ. En las estipulaciones se atiende al tiempo en que contratamos.

Nemo cogi potest ut vicino prossit sed ne noccat. Nadie está obligado a beneficiar al vecino, sino a no perjudicarlo.

Admitida la consecuencia, se admite el antecedente.

La jubilación del actor, consecuencia de su nombramiento de funcionario y ejercicio del cargo - antecedente- no le es beneficiosa 
y sí negativa y contraria a sus expectativas de futuro en el servicio activo.

En toda desviación de poder se tipifica un agravio.

Si se comparan los derechos pasivos en el campo social o laboral -entidades privadas, paraestatales o monopolios - y los del funcionariado público, comprobamos la magnitud de la desproporción y desigualdad de trato en la asignación de pensiones, hasta el punto de que en las primeras se triplica y multiplica el haber pasivo proveniente de la seguridad social y de las mutuales, superando hasta cantidades exorbitadas el límite establecido como máxima precepción por jubilación de los funcionarios. $Y$ ello sin haberse exigido a los primeros pruebas de acceso, de oposición, titulación adecuada, etc., que por su notoriedad ponen más en relieve aún la postergación y el desprecio para el servidor de la Administración pública.

El curso del procedimiento se ajustará a los trámites ordinarios que con carácter general previenen los artículos 359 y 372.3 de la Ley de Enjuiciamiento Civil y 61.1.- 80 y 81 de la Ley Jurisdiccional.

Sententia de finit totam litem y deben decidir todos los puntos litigiosos legalmente propuestos (TS 15 de noviembre de 1889; 25 de abril de 1896).

Sententia debet esse conformis libello; deben ser congruentes.

«Las sentencias no dan sino.que declaran derechos preexistentes» (Digesto Libro VIII, título V, ley 8. $^{\mathrm{a}}$, párrafo 4.o. STS 13 de abril de 1861).

\section{CONCLUSION}

A modo de colofón completamos el estudio con las siguientes citas:

BOQUERA OLIVER se inclina por calificar la relación Administraciónfuncionario como de "contrato», carácter que se opone - dice- al de relación estatutaria o de compromiso recíproco.

En la misma línea Alvarez Gendin Tratado Foral de Derecho Administrativo, tomo III, página 203; BARRACHINA Curso de Derecho Administrativo de 1985.

Entre otras aportaciones anotamos:

"El Derecho al cargo", en Documentación Administrativa, número $123 / 1968$, p. 7983.

"La carrera Administrativa», en Documentación Administrativa, número 104/1975, GONZÁLEZ-HABA.

Revista General Legislativa y Jurisprudencial. Madrid, número $144 / 1924$. 
Libro de variaciones del Derecho y Política. FERnANDEZ de VELASCO. 1932, pp. 34-35.

«Relaciones del servicio en los funcionarios públicos», en Revista de la Administración Pública, número 13/1954, pp. 53-102.

"Concepto de Funcionario y relación de la Función Pública», en Revista de la Administración Pública, número 44/1964, pp. 9-24.

Naturaleza de la relación jurídica que une al funcionario con la Administración del Estado. GASCÓN y MARiN, pp. 187-212.

«Naturaleza jurídica de la relación del funcionario público con el Estado", en Revista de la Universidad Oviedo. 1948, pp. 75-111.

El diario $A B C$, de 4 de enero de 1987, p. 47, comentando la sentencia de la Sala Quinta del Tribunal Supremo de la que fue ponente el Magistrado señor Fernández Díaz sobre el tema de la jubilación anticipada de los funcionarios públicos.

El comentarista tras reseñar que una sentencia del Tribunal Supremo no es "fuente de derecho" - se precisan dos o más-, y considerar que el artículo 164.1 de la Constitución, en lo que toca a cosa juzgada, está aplicado al caso de un modo un tanto forzado porque la sentencia que juzga ha incurrido en incongruencia; resume los argumentos de una defensa jurídica eficaz del derecho a la presencia activa de los funcionarios -en ese caso civiles del Estado - hasta la edad de setenta años.

El articulista manifiesta:

El derecho nace tras confirmarse una larga tradición, que declara y se establece en el artículo 39 de la Ley de Funcionarios Civiles de 1964. Se está refiriendo a los funcionarios del Estado.

«Ese derecho que no es expectativa figura además asegurado por el Estado en el artículo 63 de dicha Ley; "..." y sin condición alguna asegura al funcionario de carrera el derecho al cargo y todos los inherentes al mismo que la ley establece»; «la duración es inherente al aseguramiento pues sin ella no habría seguridad...»

«Todos los Poderes públicos, cuyo conjunto es el Estado, están implicados en la garantía. El poder legislativo también como parte del Estado.»

«Un Estado de Derecho está obligado a someterse al Derecho, esto es a cumplir las obligaciones que contrae. Los poderes públicos están sometidos a la Constitución, así como al resto del ordenamiento jurídico; en particular el derecho de Obligaciones con lo que éste impone para los casos de incumplimiento..."

«De haber sido derogado el artículo 3. de la Ley antigua se habría incumplido una obligación asumida lícita y válidamente y sin condición suspensiva alguna; la derogación constituiría al Estado en reo de incumplimiento con la consiguiente obligación de compensar...» 
«No se ha producido la derogación de ese artículo $63, \ldots$ ni cabe pensar que le afecte la remisión genérica de la Ley de Medidas para la Reforma de la Función Pública a "otras disposiciones". Al no haber derogación, tal artículo forma parte del Estatuto Jurídico de los Funcionarios Civiles del Estado...”

«La contradicción entre el artículo 63 antiguo y el artículo 33 nuevo puede resolverse mediante acto interpretativo ordinario por los jueces ordinarios.»

Aunque el comentarista afirma no ser aplicable a los funcionarios de la Administración local ni a los jueces y magistrados por carecer de un artículo como el citado 63 de la Ley 315/1964, esto no es así por cuanto preexiste un ordenamiento peculiar y especial de los funcionarios de los cuerpos nacionales, hoy funcionarios de Habilitación Nacional y de los funcionarios de Administración en general, que desde 1924 vienen expresamente reconociendo esos derechos y entre ellos en particular el de permanencia en el cargo y de jubilación a los setenta años; si la Ley de la Función Pública, según el comentarista, no ha derogado en ese punto la normativa de los funcionarios públicos o civiles del Estado, mucho menos puede afectar y derogar a esa normativa específica de los funcionarios de la Administración local y de otros de la Administración central; ... en parecido sentido y en el propio diario $A B C$ de enero de 1987, sobre el mismo tema de la jubilación por edad, y barajando idénticos artículos de la Ley 30/1984, con referencia a sentencia del Tribunal Constitucional de 29 de julio de 1986 , recurso $938 / 1985$ contra la totalidad de la Ley 6/1985, de 1 de julio, Orgánica del Poder Judicial, acerca del valor de cosa juzgada de dicha sentencia, el autor del artículo manifiesta que, a su juicio, tal decisión podría atentar al principio de igualdad reconocido en el artículo 14 de la Constitución Española al considerar no ser extensible la sentencia del Tribunal Constitucional de 2 de julio de 1981 que niega relación de identidad y de naturaleza entre las materias laboral y la funcionarial; y abundando en la opinión que mantenemos concluye: «urge, pues, que el Tribunal Constitucional se pronuncie y que, sobre todo, quede bien aclarado si los funcionarios tienen derecho a algún tipo de compensación, como así lo reconoció el Defensor del Pueblo, y si realmente, cuando se produce la edad de jubilación, es una expectativa de derecho e intereses patrimoniales o una realidad que en ese mismo instante deja de percibir".

SALUSTIANO del CAMPO en un artículo que titula "Jubilación y discriminación», con referencia al artículo 35 de la Constitución, afirma: «... leyéndolo subsiste la duda de si serán o no anticonstitucionales las discriminaciones basadas en la raza, la religión, la opinión o cualquiera otra circunstancia personal y social de las mencionadas por el artículo 14 cuando determina que los españoles somos iguales

REVISTA DE ESTUdios. -10 
ante la Ley, sin distinguir si ésta es civil, penal, mercantil o laboral» (diario $A B C$ de diciembre de 1987).

En recurso contencioso-administrativo ante la Sala Segunda de la Audiencia Territorial de Madrid contra resoluciones del Ministerio de Administración Territorial y de la MUNPAL, se anulan esas decisiones y se declara el derecho del recurrente a la jubilación a los setenta años (véase Revista Certamen núm. 523, p. 440).

Entre otros pronunciamientos la sentencia del Tribunal Supremo, Sala Quinta, de los Contencioso-Administrativo de 29 de noviembre de 1986, artículo 6.643, rechaza el carácter de derecho a la jubilación a los setenta años; mas examinando el contenido se observa cómo esa declaración se formula sin entrar en el fondo de la cuestión debatida y controvertida por excepción formal o procesal.

La violación, pues, contractual o extracontractual o estatutaria, que tanto se ha repetido, es la que da origen a la indemnización compensatoria de unos derechos legítimamente consumados - ¿adquiridos?-, producto de un atípico compromiso o convenio sui generis, pero que la Ley implicitamente refrenda y ampara, porque realmente existe.

A estos derechos se refiere la sentencia de 8 de mayo de 1987 (art. 3.316/1987) en un supuesto que dilucida la contradicción entre una Ley y urı Reglamento acerca de la aplicación o no del tope de jubilación forzosa de un empleado a los sesenta y cinco años o a los setenta años.

La sentencia del Tribunal Constitucional de 10 de noviembre de 1986 (art. 6.183), aceptando recurso de amparo a través de la Ley Especial 62/1978 reconoce el derecho a ser gratificado en base al principio de igualdad ante la ley en la discusión surgida entre dos funcionarios de la Administración local.

Recientemente la Sala Primera de la Audiencia Territorial de Valencia, al resolver el recurso número 30/1986 por sentencia número 84/1987, en un caso de jubilación forzosa por edad en aplicación de la Ley 30/1984, de 2 de agosto, y en cuyo suplico se pidió la declaración de disconformidad de los actos de la Administración con la Constitución, y consecuentemente su anulación, o se indemnice en la cuantía que instada en el recurso, contundentemente declarada que «la ley no establece indemnización, pero tampoco la prohíbe por lo que si efectivamente se han producido daños por ese hecho cabrá la indemnización, de conformidad con la doctrina de la responsabilidad de la Administración del Estado» (epígrafe 8048 Edersa).

En cuanto al equilibrio económico de una concesión y el deber de la Administración de mantener dicho nivel económico mediante subvención al concesionario la sentencia más reciente que no consta es la del Tribunal Supremo de 20 de diciembre de 1986 (Aranzadi, 1175). 
Es importante destacar que la esencia jurídica y política de esos derechos la sanciona a nivel internacional el pacto de "Derechos Económicos Sociales y Culturales del Tratado de Roma» (art. 2, 117 y 118 y el art. 35.1 de la Constitución Española).

En ese pacto ratificado por la Comunidad Económica Europea se consagran los principios de prevalencia normativa, imposibilidad de alteración unilateral de un contrato, el de pactum sum servanda, mantenimiento del equilibrio económico de toda relación consorcial, extracontractual o estatutaria por imponderables o causas eventuales no imputables a la parte dañada; la compensación por «elevación acelerada» del nivel de la vida; política del pleno empleo, etc. Dicho Pacto fue ratificado por España en disposición publicada en el Boletín Oficial del Estado 103/77, de 30 de abril, y recogido en el artículo 96 de nuestra Constitución.

Creemos que uno de los puntos cruciales de la litis descansa en el suplico, y ante la vaguedad de un comentario generalizado dada la pluralidad de funcionarios, preferimos ceñirnos textualmente a este modelo tipificado.

\section{SUPLICO}

\section{SE DECLARE:}

A) 1. Que el recurrente don de años, nacido el día ingresó en la Administración por oposición, con sujeción a las bases y convocatoria del Ministerio publicadas en el Boletín Oficial del Estado número quedando integrado en dicho Cuerpo, e inscrito en el escalafón con el número publicado en el mismo diario oficial de $y$ asumiendo en su primer destino en propiedad la plaza de con los derechos, deberes, prestaciones y contraprestaciones inherentes a dicho cargo.

2. - Que entre otras condiciones asignadas a la plaza que obtuvo el recurrente por oposición y cuyo cargo asumió en virtud del ordenamiento legal vigente a su ingreso, figuraban las de inamovilidad y jubilación forzosa al cumplir la edad de setenta años y la percepción de los reglamentarios derechos activos y pasivos.

3. a a) Que al anticiparse la jubilación forzosa por edad, pasando de los setenta años a los sesenta y cinco años, se produjo una alteración en la situación jurídica subjetiva e 
individual del reclamante, y una repercusión en sus haberes activos y pasivos que le correspondían, y en consecuencia en su patrimonio, según el ordenamiento legal vigente a su ingreso.

b) Que el montante económico a que asciende la repercusión y afectación que la alteración a que se refiere el extremo anterior, será deducido y cuantificado con sujeción a las bases y pormenores instrumentados en el extremo de este recurso, en y por el trámite procesal del incidente de ejecución de sentencia.

B) Subsidiariamente en el improbable supuesto de no darse lugar a los pedimentos del apartado A), en todo caso y con el fin de reestablecer la situación jurídica subjetiva e individualizada del recurrente, se dicte sentencia con arreglo a los siguientes pronunciamientos:

1) Declarar que el ingreso del demandante como funcionario y la asunción a consecuencia del mismo del desempeño del cargo, se llevó a efecto con arreglo al ordenamiento legal que se cita en el extremo _____ de éste recurso.

2) Declarar que en el ordenamiento legal constatado en el apartado anterior, entre las condiciones inherentes al cargo que el reclamante obtuvo por oposición y desempeñó hasta su jubilación, figuraban las de inamovilidad y jubilación forzosa a la edad de setenta años, con los haberes activos y pasivos reglamentarios.

3) Declarar que al recurrente le asiste el derecho de permanecer, sin solución de continuidad, como funcionario activo con los derechos asignados al cargo y función que desempeñaba al ser jubilado a los sesenta y cinco años, hasta que cumpla setenta, o en la plaza a la que pudiera acceder reglamentariamente por concurso de traslado o por otra modalidad legal de destino, durante el transcurso de ese período.

4) En el supuesto de no accederse a la continuidad y permanencia en la plaza a que se refiere el extremo anterior: Declarar que el actor, al ser jubilado por la Administración a los sesenta y cinco años, y no a los setenta, ha motivado la alteración y transtorno en su patrimonio, y ha ocasionado una discriminación de sus ingresos retributivos, cuyo montante se deducirá y fijará con arreglo a las bases y pormenores contenidos en el extremo de este recurso, en el incidente de ejecución de sentencia, y que deberá serle abonado en la forma que igualmente se determine en esa fase. de ejecución. 
C) En cualquier supuestọ, se condene a la Administración tras los trámites que se llevan a efecto en la ejecución de sentencia.

Este trabajo no tiene otra aspiración que la de someterlo a consideración y criterio de los compañeros a quienes pueda interesar: Esperamos su colaboración y en especial sus observaciones $y$ reparos.

De antemano nuestro agradecimiento y la promesa y el ofrecimiento de que estamos prestos a rectificar. 
